\title{
Automation of Maintaining a Smart Reference Book of Tool Setups for the Development of Control Programs for CNC Machine
}

\author{
Yuri V. Polyanskov ${ }^{1}$, Oleg V. Zheleznov ${ }^{1, *}$, Aleksey A. Blyumenshteyn ${ }^{1}$, and \\ Ilya A. Sergeev ${ }^{1}$ \\ ${ }^{1}$ Ulyanovsk State University, Ulyanovsk, 432048, Russia
}

\begin{abstract}
The article is devoted to the problems of increasing the efficiency of technological preparation production through the development and implementation of an electronic database of tool setups. In the paper describes the advantages and disadvantages of the existing process for the development of NC-programs, and a methodology for automating the process of conducting tool setups, allowing to reduce the laboriousness of designing manufacturing processes for machining of parts on $\mathrm{CNC}$ machines. And also, the calculation results are given the economic efficiency of the project and the prospects for its development.
\end{abstract}

\section{Introduction}

Currently, the focus of the largest technology corporations in the world is the fourth industrial revolution or "Industry 4.0". Within the framework of the fourth industrial revolution, the socalled digital production is becoming a key aspect. Digital manufacturing involves end-toend automation of processes, including the early stages of product development. End-to-end automation becomes possible thanks to the digitalization of all information about the product, its production and operation processes creating a so-called "digital twin" [1]. This facilitates the use of virtual simulation at each stage of the product life cycle [2], which allows identifying possible design problems, finding the optimal parameters of manufacturing processes (MP) [3] and checking the reliability of the design under different operating modes. Digital information is easier to transform and transfer, which significantly reduces development time. Manufacturing processes [4] described in digital form make it possible to use massively equipment operating in automatic mode, and this is a predictable quality. Digital manufacturing makes it possible to change quickly and cheaply production facilities to meet changing conditions, whether it be changes in market demand for products, changes in the supply chain of components or equipment failure. This makes it possible to manufacture products for the individual needs of customers with the price of the final product comparable to the price of large-scale production.

In the context of the transition to digital production, aircraft manufacturers are striving to modernize the technological preparation of production (TPP) through automation [5].

\footnotetext{
* Corresponding author: olegulsu@mail.ru
} 
Automation of TPP [6] includes the automation of such functions as the development of manufacturing processes, the design of technological equipment and data processing.

\section{Tool management in machining shops of an aircraft building enterprise for CNC machines}

The actual problem of domestic enterprises is the process of maintaining and planning the tool economy. The specialists responsible for this stage of production are faced with an important task - to use all available reserves for the timely and uninterrupted provision of production with all types of technical equipment, organization of its storage, operation and repair. Since it is precisely on the quality of these tasks that the efficiency of the entire production depends.

Currently, most machine-building enterprises use $\mathrm{CNC}$ machines [7]. For their effective use at enterprises, it is necessary to improve the system of maintaining the enterprise tool.

When analyzing the process of maintaining the tool in most shops of machining industries, it was revealed that the process engineer does not always have information about the availability of the required tool. When designing a tool setup (TS), the developer has to make inquiries to the bureau of the tool management to clarify the information or indicate not the specific position of the tool, but the general characteristics of the required tool. In addition, the current system does not take into account tool wear, availability in the warehouse, geometric characteristics, current state (ready to use or under repair) and current location (warehouse or production workshop), which entails the emergence of many errors in the design of manufacturing processes and the formation of tool setups. This is due to the fact that the enterprise often does not have modern tools for managing the tool management, and foreign developments in this area are not suitable for use at domestic enterprises, since they do not take into account Russian standards (GOST and IS) and there is no possibility of export and import of information in the design of manufacturing processes and the formation of tool setups, taking into account the integration with PDM and ERP-systems of the enterprise. This is especially true for defense enterprises that use proprietary software.

Based on the above problems, a decision to develop a software product for managing the enterprise's instrumental economy was made, integrated with the CAD MP system of the enterprise and Siemens NX.

\section{Development of control programs and manufacturing processes of the tool in the machining shops of an aircraft building enterprise}

One of the key stages of technological preparation of production is the development of numerical controls programs (NC) for machine tools with numerical control, since the quality of the manufactured product, the reliability of technological equipment and the efficiency of the production process as a whole depend on the developed NC program. The process of developing a NC consists of four main stages:

1. Preparation of initial data.

2. Development of NC program.

3. Verification of the $\mathrm{NC}$ program on the computer.

4. Verification of NC program on the machine.

After analyzing the second stage of the process of developing an $\mathrm{NC}$ programs for $\mathrm{CNC}$ machine tools, the problems (Table 1) that the developer of the $\mathrm{NC}$ is facing with were identified. 
Table 1. Problems at the stage of development of the NC programs.

\begin{tabular}{|c|c|c|c|}
\hline № & Item & Problem & Cause \\
\hline \multirow[t]{2}{*}{1.} & \multirow{2}{*}{$\begin{array}{l}\text { Calculation of tool } \\
\text { paths }\end{array}$} & Insufficient accuracy of calculations & \multirow{5}{*}{$\begin{array}{l}\text { Lack of data import } \\
\text { support; } \\
\text { Lack of relevant databases } \\
\text { and knowledge bases; } \\
\text { Low level of developer } \\
\text { skills. }\end{array}$} \\
\hline & & $\begin{array}{l}\text { Errors in calculating the control points } \\
\text { of the tool path }\end{array}$ & \\
\hline \multirow[t]{3}{*}{2.} & \multirow{3}{*}{$\begin{array}{l}\text { Selection of the } \\
\text { type of operations } \\
\text { and initial } \\
\text { calculation }\end{array}$} & Tool assignment errors & \\
\hline & & Errors when assigning cutting mode & \\
\hline & & $\begin{array}{l}\text { Errors when choosing a processing } \\
\text { strategy }\end{array}$ & \\
\hline \multirow[t]{3}{*}{3.} & \multirow[t]{3}{*}{$\begin{array}{l}\text { NC program coding } \\
\text { in a universal } \\
\text { format }\end{array}$} & $\begin{array}{l}\text { Lack of necessary technological } \\
\text { commands and operations }\end{array}$ & $\begin{array}{l}\text { Lack of relevant } \\
\text { databases and knowledge } \\
\text { bases. }\end{array}$ \\
\hline & & Syntax errors & \multirow{5}{*}{$\begin{array}{l}\text { Negligence of the } \\
\text { performer; } \\
\text { Low level of developer } \\
\text { skills. }\end{array}$} \\
\hline & & Errors in writing command codes & \\
\hline \multirow[t]{3}{*}{4.} & \multirow{3}{*}{$\begin{array}{l}\text { Input of initial } \\
\text { information and } \\
\text { part geometry }\end{array}$} & $\begin{array}{l}\text { Errors when entering information about } \\
\text { the relative position of elements }\end{array}$ & \\
\hline & & Loss of data & \\
\hline & & Errors entering dimensions & \\
\hline 5. & $\begin{array}{l}\text { Choice of } \\
\text { equipment for } \\
\text { processing }\end{array}$ & Wrong choice of equipment & $\begin{array}{l}\text { Inconsistency in the work } \\
\text { of divisions of the } \\
\text { enterprise; } \\
\text { Lack of decision support } \\
\text { tools. }\end{array}$ \\
\hline
\end{tabular}

After conducting a detailed analysis of the identified problems and their causes, as well as the impossibility of using ready-made solutions due to their high cost, lack of functionality or the impossibility of integrating them into the existing CAD system of the enterprise. The listed problems can be solved by developing your own software, consisting of the following modules:

- a module for managing enterprise resources;

- a module for conducting tool setups, including a decision support system for the design of tool setups;

- an integration module with the Siemens NX CAD system.

For the developed system, a diagram of the interaction of the developed software with the enterprise systems was drawn (Fig. 1).

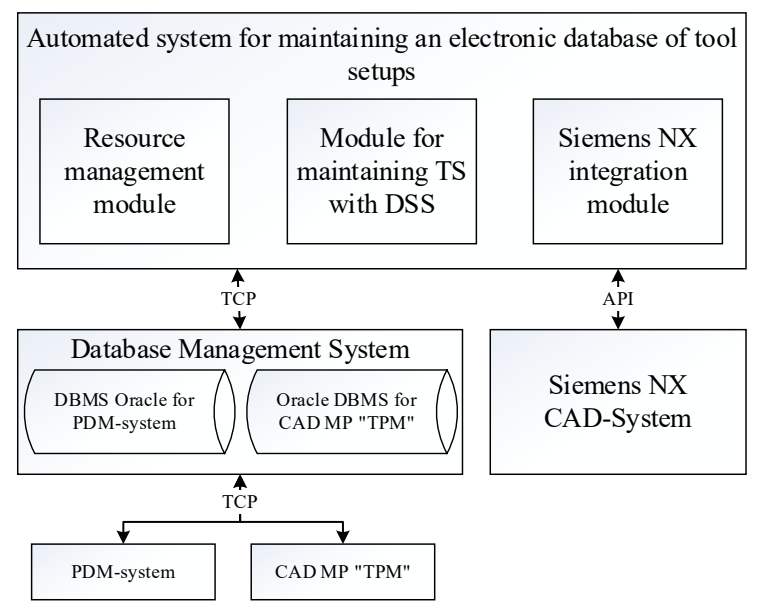

Fig. 1. Software interaction scheme 
The software that includes the listed modules will completely eliminate or significantly reduce the likelihood of problems at all stages of the development of numerical control programs by using an up-to-date database of enterprise resources, simplifying the process of designing tool setups and using a decision support system when forming the composition of tool setups.

\section{Decision support system for the design of tool setups for the development of numerical control programs}

The basic principle of the decision support system (DSS) [8] is to form a tool-setting template describing the order, a list of tool groups and restrictions on tool parameters as part of the tool setting.

The algorithm for generating a tool-setting template consists of 6 stages and is presented in Table 2.

Table 2. Stages of formation of TS templates.

\begin{tabular}{|l|l|l|}
\hline № & \multicolumn{1}{|c|}{ Stage } & \multicolumn{1}{c|}{ Tasks } \\
\hline 1. & $\begin{array}{l}\text { Setting up a direct } \\
\text { correspondence between } \\
\text { CAD groups and } \\
\text { Siemens NX }\end{array}$ & $\begin{array}{l}\text { Selecting the NX Tool Type } \\
\text { Selecting an NX tool subtype } \\
\text { Editing Cutter Matching Groups } \\
\text { Determination of correspondence of CAD and Siemens NX } \\
\text { parameters }\end{array}$ \\
\hline 2. & $\begin{array}{l}\text { Create cutting tool } \\
\text { groups }\end{array}$ & $\begin{array}{l}\text { Edit the list of cutter group names } \\
\text { Edit the corresponding group of CADs } \\
\text { Edit the list of TS element group names } \\
\text { Edit the corresponding group of CADs }\end{array}$ \\
\hline 3. & $\begin{array}{l}\text { Creation of tool setup } \\
\text { templates }\end{array}$ & $\begin{array}{l}\text { Select the name of the cutting tool group } \\
\text { Selecting the name of the element tool setup } \\
\text { Form the tool setup template } \\
\text { Add tool setup template } \\
\text { Add NX types and subtypes } \\
\text { Add the tool setup template image }\end{array}$ \\
\hline 4. & $\begin{array}{l}\text { Configuring connection } \\
\text { rules for tool setup } \\
\text { templates }\end{array}$ & $\begin{array}{l}\text { Select tool setup template } \\
\text { Select the line to configure compatible items } \\
\text { Select the line with compatible items } \\
\text { Determine the compatible parameters of the first and second } \\
\text { elements }\end{array}$ \\
\hline 5. & $\begin{array}{l}\text { Setting up rules for } \\
\text { generating auxiliary } \\
\text { transitions for tool setup }\end{array}$ & $\begin{array}{l}\text { ID template selection } \\
\text { Selection of assembly / disassembly transition of tool setup } \\
\text { Editing the list of matching templates and transitions of assembly } \\
\text { / disassembly tool setup tool setup }\end{array}$ \\
\hline 6. & $\begin{array}{l}\text { Setting up the rules for } \\
\text { connecting equipment } \\
\text { and tools }\end{array}$ & $\begin{array}{l}\text { Selecting a group of equipment } \\
\text { Selecting a tool group } \\
\text { Determination of compatible parameters of a group of equipment } \\
\text { Determining Compatible Tool Group Parameters }\end{array}$ \\
\hline
\end{tabular}

The tool-setting design process algorithm consists of seven stages:

1. Formation of the name and description of tool setup.

2. Selecting the NX tool type.

3. Selecting the NX tool subtype.

4. Selecting the tool setup template.

5. Formation of the tool setup composition using the DSS for the selection of compatible resources. 
6. Editing the parameters of the tool from the tool setup.

7. Saving and exporting tool setup to the Siemens NX CAM module.

The formation of the composition of the tool setting is carried out using a decision support system. To describe it, we introduce the following list of sets:

- $I=\left\{P_{1}, P_{2}, \ldots, P_{N_{\text {Type }}}\right\}$ - a set of enterprise tools. Where $N_{\text {Type }}-$ is the number of types of enterprise instruments. Set I contain subsets of all kinds and types of enterprise tool management.

- $P_{i}=\left\{\begin{array}{lll}p_{11} & p_{12} & p_{1 n} \\ p_{21} & p_{22} & p_{2 n} \\ p_{m 1} & p_{m 2} & p_{m n}\end{array}\right\}-$ many tools option. Where $\mathrm{n}$ - the number of tool parameters and $\mathrm{m}$ - the number of tools in the group.

- $T=\left\{T_{1}, T_{2}, \ldots, T_{N_{T e m p}}\right\}$ - a variety of tool setting templates. Where $N_{T e m p}-$ the number of tool setting templates.

- $T_{i}=\left\{P_{1}^{\prime}, P_{2}^{\prime}, \ldots, P_{N_{E l e m}}^{\prime}\right\}$ - denote the set of elements of the tool-setting template. Where $N_{\text {Elem }}$ - is the number of elements in the tool setup.

- $P_{1}^{\prime}=\left\{P_{1 i}, P_{2 i}, \ldots, P_{n i}\right\}-$ list of tool groups defined in the template for this position in the tool setup.

Let us define the following relation $P_{i i} \subset P_{i}^{\prime} \subset I$ i.e. in the tool set-up template; a certain list of groups is defined for each position, which is suitable for use at this position as part of tool set-up.

Suppose $N_{i}=\left\{p_{1}^{1}, p_{2}^{2}, \ldots, p_{n-1}^{n-1}, p_{n}^{n}\right\}-$ tool setup assembled using $T_{i}$ template. Let $p_{1}^{1}=$ $\left\{p_{i 1}^{1}, p_{i 2}^{2}, \ldots, p_{i n}^{n}\right\}-$ be the first tool position in the tool-setting template. Then $p_{2}^{2}=$ $\left\{p_{i 1}^{2}, p_{i 2}^{2}, \ldots, p_{i n}^{2}\right\}$ - the second position in the pattern must meet one of the following rules:

- $p_{i i}^{1}=p_{i i}^{2}, p_{i i}^{1} \in p_{1}^{1}, p_{i i}^{1} \in p_{2}^{2}$;

- $p_{i i_{1}}^{2} \geq p_{i i}^{1} \geq p_{i i_{2}}^{2}, p_{i i}^{1} \in p_{1}^{1}, p_{i i_{1}}^{2}$ и $p_{i i_{2}}^{2} \in p_{2}^{2}$.

That is, each tool setting position except the first must be selected according to one of the following principles:

- $p_{i i}^{i}=p_{i i}^{i+1}, p_{i i}^{i} \in p_{i}^{i}, p_{i i}^{i+1} \in p_{i}^{i+1}$;

- $p_{i i_{1}}^{i+1} \geq p_{i i}^{i} \geq p_{i i_{2}}^{i+1}, p_{i i}^{i} \in p_{i}^{i}, p_{i i_{1}}^{i}$ и $p_{i i_{2}}^{i} \in p_{i}^{i+1}$.

\section{Integration of the catalog of tool setups with the module for automatic generation of the manufacturing process software part}

The use of the "Electronic catalog of tool setups" (Fig. 2) in the development of numerical control programs allows the process engineer to automatically form and add tool setups to the Siemens NX CAM project from the CAD system database, which significantly reduces the labor intensity of the operations performed by the process engineer during development numerical control programs.

The tool setups added to the CAM project are further used in the design of the manufacturing process and set-up chart. 


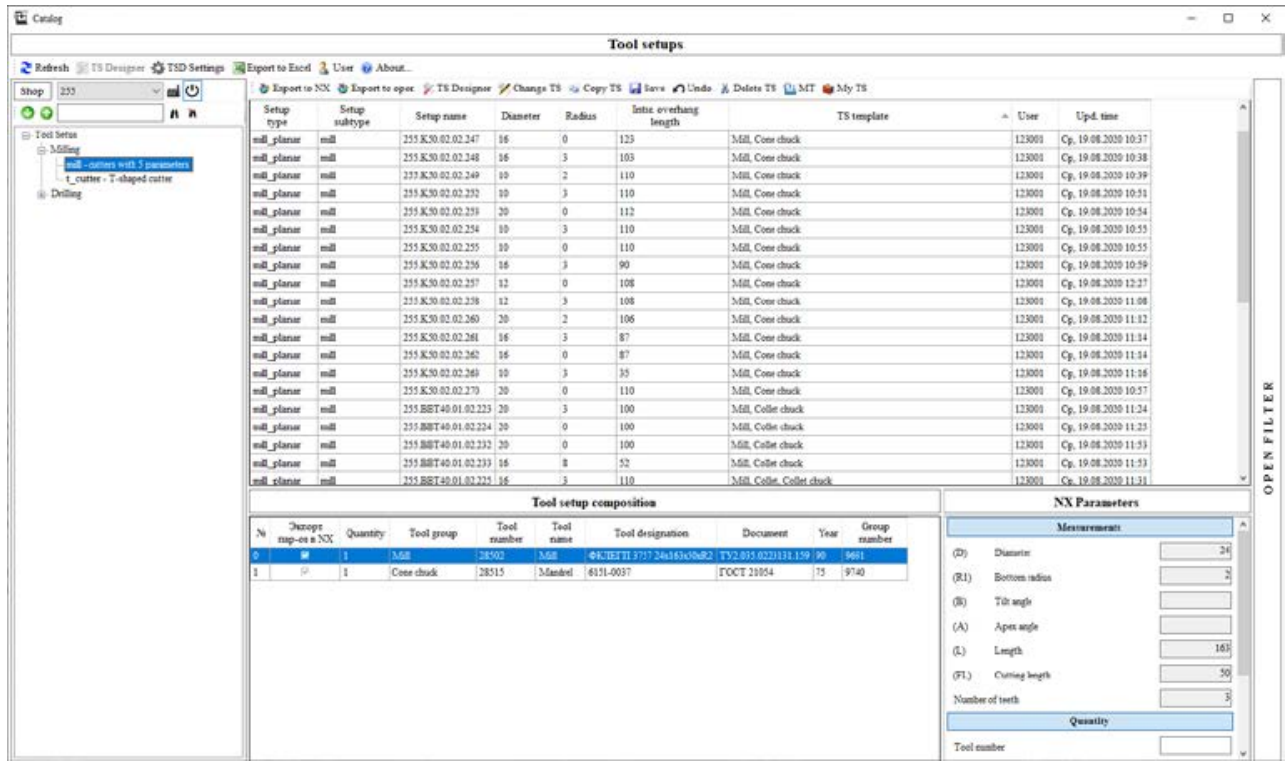

Fig. 2. The main window of the "Electronic catalog of tool setups"

\section{Conclusions}

The article describes algorithms that automatically form the composition of the tool setup. The developed decision support system based on the described algorithms will save employees from monotonous routine, using their potential more competently and rationally.

The automated system for maintaining the electronic database of tool setups has successfully passed preliminary tests at Aviastar-SP JSC. Replication of software is possible at all enterprises of the transport aviation division of public joint stock company united aircraft corporation and machine-building enterprises with a similar technological preparation of production.

The introduction of the "Electronic catalog of tool setups" at machine-building enterprises improves the quality of labor and its productivity. The developed software reduces the time required for the design of tool set-ups by $30 \%$ and the probability of errors in choosing the composition of the tool set-up, which are allowed due to the human factor.

The calculation of the annual savings [9], one-time capital costs for the development of the software product and the annual economic effect showed that the payback period of the developed software is less than 4 years. Moreover, with an increase in the number of designed manufacturing processes per year by $25 \%$, the payback period of the software will decrease to $2-3$ years.

The developed software, according to preliminary estimates, will increase the efficiency of technological preparation of the existing production by automating the design process and a decision support system when choosing the composition of tool setups. This provides significant progress along the path of digital transformation and creates the preconditions for the implementation of MES systems and multi-agent technologies that allow rational management of production processes and independently make effective decisions that reflect the balance of participants in the production process. 


\section{References}

1. Borovkov A. I., Ryabov YU. A., Kukushkin K. V., Maruseva V. M., Kulemin V. YU. (2019) Cifrovye dvojniki i cifrovaya transformaciya predpriyatij OPK // Vestnik vostochno-sibirskoj otkrytoj akademii. 2019. № 32. [URL: http://vsoa.esrae.ru/2061150]

2. Anikin A.S. etc. The virtual enterprise of the Tomsk Polytechnic University based on modern information technologies // Bulletin of the Tomsk Polytechnic University. 2006. T. 309. No. 7. S. 152-155.

3. Samsonov O.S. (2014) Development of information support for the design and modeling of technological processes for the assembly of aviation equipment / O.S. Samsonov, M.O. Shenaev, M.E. Sautenkov, D.S. Vorontsov, A.N. Petrina // Bulletin of the Samara Scientific Center of the Russian Academy of Sciences. - 2014. - No. 1 (5). - S. 1602.

4. Evseev A.N. (2013) Theoretical foundations of production technology: Methodological manual for students studying the discipline "Fundamentals of technological processes and production" // Ulyanovsk: UISU, 2013 .-- 83 p.

5. Burtsev V.M. and et al. (2011). Tekhnologiya mashinostroeniya. T. 1: Osnovy tekhnologii mashino-stroeniya "Technology of Machine Building. Vol. 1: Basics of Machine Building Technology". Bauman MSTU Publ.

6. Polyanskov Y.V., Lutoshkin I.V., Blyumenshteyn A.A. (2019) The model of choice of machine retaining devices for technological preparation of production // Journal of Physics: Conference Series,1399 (2019) 033063, doi:10.1088/17426596/1399/3/033063.

7. Blyumenshteyn A.A., Zheleznov O.V., Chernikov M.S. (2012) "Development of an automated lifecycle management system USP” // Vestnik SSAU - Samara: №5 (35) part 1 - 2012. C. 266-270.

8. Vishnekov A.V., Kurilova N.S., Safonova I.E., Shteinberg V.I. (2002) Multipurpose tasks of making design decisions: Textbook. - MGIEM. - M., 2002. -- 101 p.

9. Abryutina, M.S. (2018) Analysis of the financial and economic activity of the enterprise // M.S.Abryutina, A.V. Grachev A.V.M .: Delo and Service, 2018.256 p. 